\title{
Bioactivity and chemical characterization in hydrophilic and lipophilic compounds of Chenopodium ambrosioides $\mathrm{L}$.
}

Lillian Barros $^{\text {aौ }}$, Eliana Pereira ${ }^{\text {ał }}$, Ricardo C. Calhelha ${ }^{\mathrm{a}, \mathrm{b}}$, Montserrat Dueñas ${ }^{\mathrm{c}}$, Ana Maria Carvalho ${ }^{\mathrm{a}}$, Celestino Santos-Buelga ${ }^{\mathrm{c},{ }^{*}}$, Isabel C.F.R. Ferreira ${ }^{\mathrm{a},{ }^{,}}$

${ }^{a}$ Centro de Investigação de Montanha (CIMO), ESA, Instituto Politécnico de Bragança, Campus de Santa Apolónia, 1172, 5301-855 Bragança, Portugal.

${ }^{b}$ Centro de Química, Universidade do Minho, Campus de Gualtar 4710-057 Braga, Portugal.

${ }^{c}$ GIP-USAL, Facultad de Farmacia, Universidad de Salamanca, Campus Miguel de Unamuno, 37007 Salamanca, Spain.

"Both authors contributed equally.

*Authors to whom correspondence should be addressed (e-mail: iferreira@ipb.pt, telephone +351273303219 , fax +351273325405 ; e-mail: csb@usal.es; telephone +34 923 294537; fax +34 923 294515). 


\begin{abstract}
The bioactive properties (antioxidant and antitumour activities, and hepatotoxicity) of the infusion and methanolic extracts of Chenopodium ambrosioides L., a plant commonly used in Portuguese folk medicine, were compared. The chemical composition in hydrophilic (sugars, organic acids and phenolic compounds) and lipophilic (fatty acids and tocopherols) fractions were determined. In general, the infusion revealed higher antioxidant activity, while the methanolic extract was the only one showing antitumour effects against colon, cervical and hepatocellular carcinoma cell lines. No toxicity in non-tumour cells was observed either for the infusion or the extract. The studied plant proved to be a good source of natural antioxidants and other bioactive compounds, which may have industrial use. As far as we know, this is the first detailed chemical characterization and bioactivity evaluation of $C$. ambrosioides methanolic extract and infusion.
\end{abstract}

Keywords: Chenopodium ambrosioides L.; Antioxidant activity; Antitumour activity; Chemical compounds 


\section{Introduction}

Oxidative stress is an imbalance between the generation of reactive oxygen species (ROS; which include unstable oxygen radicals such as superoxide radical and hydroxyl radical and non-radical molecules like hydrogen peroxide) and the body's antioxidant defence capacity, having an important role in normal cell functioning. When produced in excess ROS can have harmful effects, affecting cellular lipids, proteins and DNA, leading to their modification, and often destruction, and inhibiting their normal function (Valko et al., 2007; Rosenfeldt et al., 2013). Relevant diseases such as cancer, diabetes, cirrhosis, heart disease or dementia disorders, as well as aging process have been associated with the uncontrolled production of free radicals (Valko et al., 2007; Halliwell, 2012).

Some plants traditionally used have medicinal properties with great potential for therapeutic applications in the treatment of some of the aforementioned diseases, since they are a natural source of bioactive compounds, including antioxidants, such as polyphenols, vitamins, carotenoids, unsaturated fatty acids and sugars, which can be useful for various applications, especially as food additives and in health promotion as ingredients in formulations of functional foods and nutraceuticals (Ramarathnam, Osawa, Ochi, \& Kawakishi, 1995; Skerget et al., 2005).

Chenopodium ambrosioides L. (Amaranthaceae; syn: Dysphania ambrosioides (L.) Mosyakin \& Clemants) is an example of a plant formerly used in Portuguese traditional medicine, normally consumed as infusion of its dried leaves and flowering stems. It is an exotic plant from Central and South America that in former times was introduced by migrants from those countries. Nowadays the species has escaped to wild and can be occasionally found in pathways and near homegardens. It has diverse pharmacological 
applications in the treatment of influenza, cold or gastrointestinal and respiratory ailments, as well as vomiting, antihelmintic, healing of skin ulceration caused by Leishmania species, anti-inflammatory and antitumor properties (Nascimento et al., 2006; Cruz et al., 2007; Carvalho, 2010; Kamel, El-Emam, Mahmoud, Fouda, \& Bayaumy, 2011).

Studies on chemical characterization and bioactivity evaluation of this plant, particularly in the most consumed form (infusion) are scarce. The present work aims to characterize the chemical composition of C. ambrosioides in hydrophilic (sugars, organic acids and phenolic compounds) and lipophilic (fatty acids and tocopherols) molecules, as also some bioactive properties (antioxidant and antitumour activities, and hepatotoxicity) of its infusion and methanolic extract.

\section{Materials and methods}

\subsection{Sample}

Chenopodium ambrosioides L. (Amaranthaceae) (English names: Epazote, wormseed, Jesuit's tea, Mexican tea; Local names: Té; chá-bravo; chá de Santa Marinha), also known as Dysphania ambrosioides (L.) Mosyakin \& Clemants, (Amaranthaceae), used to be cultivated in homegardens in Bragança (Northeastern Portugal). Nowadays it is less frequent in gardens and there are some specimens growing wild nearby the local villages. However, if available, inflorescences and upper leaves are still wild gathered, dried and used as herbal infusions. The material was collected in Varge (Bragança) from different plants considering the species availability and local consumers' criteria for medicinal use. A sample was made putting together all the material from several specimens. 
Voucher specimens are deposited at the Herbarium of the Escola Superior Agrária de Bragança (BRESA). The samples were lyophilized (FreeZone 4.5, Labconco, Kansas City, MO, USA), reduced to a fine dried powder (20 mesh) and mixed to obtain a homogenate sample.

\subsection{Standards and Reagents}

Acetonitrile (99.9\%), n-hexane (97\%) and ethyl acetate $(99.8 \%)$ were of HPLC grade from Fisher Scientific (Lisbon, Portugal). The fatty acids methyl ester (FAME) reference standard mixture 37 (standard 47885-U) was purchased from Sigma (St. Louis, MO, USA), as also were other individual fatty acid isomers and standards: Lascorbic acid, tocopherols ( $\alpha-, \beta-, \gamma$-, and $\delta$-isoforms), sugars $(\mathrm{D}(-)$-fructose, $\mathrm{D}(+)-$ melezitose, $\quad \mathrm{D}(+)$-sucrose, $\quad \mathrm{D}(+)$-glucose, $\quad \mathrm{D}(+)$-trehalose and $\mathrm{D}(+)$-raffinose pentahydrate), organic acids and trolox (6-hydroxy-2,5,7,8-tetramethylchroman-2carboxylic acid). Phenolic compounds were purchased from Extrasynthèse (Genay, France). Racemic tocol, $50 \mathrm{mg} / \mathrm{mL}$, was purchased from Matreya (Pleasant Gap, PA, USA). 2,2-Diphenyl-1- picrylhydrazyl (DPPH) was obtained from Alfa Aesar (Ward Hill, MA, USA). Foetal bovine serum (FBS), L-glutamine, hank's balanced salt solution (HBSS), trypsin-EDTA (ethylenediaminetetraacetic acid), penicillin/streptomycin solution (100 U/mL and $100 \mathrm{mg} / \mathrm{mL}$, respectively), RPMI-1640 and DMEM media were from Hyclone (Logan, USA). Acetic acid, ellipticine, sulphorhodamine B (SRB), trypan blue, trichloroacetic acid (TCA) and Tris were from Sigma Chemical Co. (St Louis, MO, USA). Water was treated in a Milli-Q water purification system (TGI Pure Water Systems, Greenville, SC, USA). All other chemicals and solvents were of analytical grade and purchased from common sources. 


\subsection{Evaluation of bioactive properties}

2.3.1. Samples preparation. The methanolic extract was obtained from the lyophilized plant material. The sample $(1 \mathrm{~g})$ was extracted by stirring with $25 \mathrm{~mL}$ of methanol $(25$ ${ }^{\circ} \mathrm{C}$ at $150 \mathrm{rpm}$ ) for $1 \mathrm{~h}$ and subsequently filtered through Whatman No. 4 paper. The residue was then extracted with $25 \mathrm{~mL}$ of methanol $\left(25^{\circ} \mathrm{C}\right.$ at $\left.150 \mathrm{rpm}\right)$ for $1 \mathrm{~h}$. The combined methanolic extracts were evaporated at $40{ }^{\circ} \mathrm{C}$ (rotary evaporator Büchi R-210, Flawil, Switzerland) to dryness.

The infusion was also obtained from the lyophilized plant material. The sample (1 g) was added to $200 \mathrm{~mL}$ of boiling distilled water and left to stand at room temperature for 5 min, and then filtered under reduced pressure. The obtained infusion was frozen and lyophilized.

Methanolic extract and infusion were redissolved in i) methanol and water, respectively (final concentration $2.5 \mathrm{mg} / \mathrm{mL}$ ) for antioxidant activity evaluation, or ii) water (final concentration $8 \mathrm{mg} / \mathrm{mL}$ ) for antitumour activity evaluation. The final solutions were further diluted to different concentrations to be submitted to distinct bioactivity evaluation in in vitro assays. The results were expressed in i) $\mathrm{EC}_{50}$ values (sample concentration providing $50 \%$ of antioxidant activity or 0.5 of absorbance in the reducing power assay) for antioxidant activity, or ii) $\mathrm{GI}_{50}$ values (sample concentration that inhibited $50 \%$ of the net cell growth) for antitumour activity. Trolox and ellipticine were used as positive controls in antioxidant and antitumour activity evaluation assays, respectively.

2.3.2. Antioxidant activity. DPPH radical-scavenging activity was evaluated by using an ELX800 microplate reader (Bio-Tek Instruments, Inc; Winooski, VT, USA), and calculated as a percentage of $\mathrm{DPPH}$ discolouration using the formula: $\left[\left(\mathrm{A}_{\mathrm{DPPH}^{-}}\right.\right.$ 
$\left.\left.A_{S}\right) / A_{D P P H}\right] \times 100$, where $A_{S}$ is the absorbance of the solution containing the sample at $515 \mathrm{~nm}$, and $\mathrm{A}_{\mathrm{DPPH}}$ is the absorbance of the DPPH solution. Reducing power was evaluated by the capacity to convert $\mathrm{Fe}^{3+}$ into $\mathrm{Fe}^{2+}$, measuring the absorbance at $690 \mathrm{~nm}$ in the microplate reader mentioned above. Inhibition of $\beta$-carotene bleaching was evaluated though the $\beta$-carotene/linoleate assay; the neutralization of linoleate free radicals avoids $\beta$-carotene bleaching, which is measured by the formula: $\beta$-carotene absorbance after $2 \mathrm{~h}$ of assay/initial absorbance) $\times 100$. Lipid peroxidation inhibition in porcine (Sus scrofa) brain homogenates was evaluated by the decrease in thiobarbituric acid reactive substances (TBARS); the colour intensity of the malondialdehydethiobarbituric acid (MDA-TBA) was measured by its absorbance at $532 \mathrm{~nm}$; the inhibition ratio $(\%)$ was calculated using the following formula: $[(\mathrm{A}-\mathrm{B}) / \mathrm{A}] \times 100 \%$, where A and B were the absorbance of the control and the sample solution, respectively (Pinela et al., 2012).

2.3.3. Antitumour activity. Five human tumour cell lines were used: MCF-7 (breast adenocarcinoma), NCI-H460 (non-small cell lung cancer), HCT-15 (colon carcinoma), HeLa (cervical carcinoma) and HepG2 (hepatocellular carcinoma). Cells were routinely maintained as adherent cell cultures in RPMI-1640 medium containing 10\% heatinactivated FBS (MCF-7, NCI-H460 and HCT-15) and $2 \mathrm{mM}$ glutamine or in DMEM supplemented with $10 \%$ FBS, $2 \mathrm{mM}$ glutamine, $100 \mathrm{U} / \mathrm{mL}$ penicillin and $100 \mathrm{mg} / \mathrm{mL}$ streptomycin (HeLa and HepG2 cells), at $37^{\circ} \mathrm{C}$, in a humidified air incubator containing $5 \% \mathrm{CO}_{2}$. Each cell line was plated at an appropriate density $\left(7.5 \times 10^{3}\right.$ cells/well for MCF-7, NCI-H460 and HCT-15 or $1.0 \times 10^{4}$ cells/well for HeLa and HepG2) in 96well plates and allowed to attach for $24 \mathrm{~h}$. Cells were then treated for $48 \mathrm{~h}$ with various extract concentrations. Following this incubation period, the adherent cells were fixed 
by adding cold 10\% trichloroacetic acid (TCA, $100 \mu \mathrm{L}$ ) and incubated for 60 min at 4 ${ }^{\circ} \mathrm{C}$. Plates were then washed with deionised water and dried; sulphorhodamine B solution $(0.1 \%$ in $1 \%$ acetic acid, $100 \mu \mathrm{L})$ was then added to each plate well and incubated for $30 \mathrm{~min}$ at room temperature. Unbound SRB was removed by washing with $1 \%$ acetic acid. Plates were air dried, the bound SRB was solubilised with $10 \mathrm{mM}$ Tris $(200 \mu \mathrm{L})$ and the absorbance was measured at $540 \mathrm{~nm}$ in the microplate reader mentioned above (Guimarães et al., 2013).

2.3.4. Hepatotoxicity. A cell culture was prepared from a freshly harvested porcine liver obtained from a local slaughter house, and it was designed as PLP2. Briefly, the liver tissues were rinsed in hank's balanced salt solution containing $100 \mathrm{U} / \mathrm{mL}$ penicillin, 100 $\mu \mathrm{g} / \mathrm{mL}$ streptomycin and divided into $1 \times 1 \mathrm{~mm}^{3}$ explants. Some of these explants were placed in $25 \mathrm{~cm}^{2}$ tissue flasks in DMEM medium supplemented with $10 \%$ fetal bovine serum, $2 \mathrm{mM}$ nonessential amino acids and $100 \mathrm{U} / \mathrm{mL}$ penicillin, $100 \mathrm{mg} / \mathrm{mL}$ streptomycin and incubated at $37^{\circ} \mathrm{C}$ with a humidified atmosphere containing $5 \% \mathrm{CO}_{2}$. The medium was changed every two days. Cultivation of the cells was continued with direct monitoring every two to three days using a phase contrast microscope. Before confluence was reached, cells were subcultured and plated in 96-well plates at a density of $1.0 \times 10^{4}$ cells/well, and cultivated in DMEM medium with $10 \% \mathrm{FBS}, 100 \mathrm{U} / \mathrm{mL}$ penicillin and $100 \mu \mathrm{g} / \mathrm{mL}$ streptomycin (Abreu et al., 2011).

\subsection{Chemical composition in hydrophilic compounds}

2.4.1. Sugars. Free sugars were determined by high performance liquid chromatography coupled to a refraction index detector (HPLC-RI). Dried sample powder $(1.0 \mathrm{~g})$ was spiked with the melezitose as internal standard (IS, $5 \mathrm{mg} / \mathrm{mL}$ ), and was extracted with 
$40 \mathrm{~mL}$ of $80 \%$ aqueous ethanol at $80{ }^{\circ} \mathrm{C}$ for $30 \mathrm{~min}$. The resulting suspension was centrifuged (Centurion K24OR refrigerated centrifuge, West Sussex, UK) at 15,000g for $10 \mathrm{~min}$. The supernatant was concentrated at $60{ }^{\circ} \mathrm{C}$ under reduced pressure and defatted three times with $10 \mathrm{~mL}$ of ethyl ether, successively. After concentration at 40 ${ }^{\circ} \mathrm{C}$, the solid residues were dissolved in water to a final volume of $5 \mathrm{~mL}$ and filtered through $0.2 \mu \mathrm{m}$ nylon filters from Whatman (Pinela et al., 2012). The equipment of analysis consisted of an integrated system with a pump (Knauer, Smartline system 1000, Brelin, Germany), degasser system (Smartline manager 5000), auto-sampler (AS2057 Jasco, Easton, MD) and an RI detector (Knauer Smartline 2300). Data were analysed using Clarity 2.4 Software (DataApex). The chromatographic separation was achieved with a Eurospher 100-5 $\mathrm{NH}_{2}$ column $(4.6 \times 250 \mathrm{~mm}, 5 \mathrm{~mm}$, Knauer $)$ operating at $30{ }^{\circ} \mathrm{C}$ (7971 $\mathrm{R}$ Grace oven). The mobile phase was acetonitrile/deionized water, 70:30 $(v / v)$ at a flow rate of $1 \mathrm{~mL} / \mathrm{min}$. The compounds were identified by chromatographic comparisons with authentic standards. Quantification was performed using the internal standard method and sugar contents were further expressed in $\mathrm{g}$ per $100 \mathrm{~g}$ of dry weight $(\mathrm{dw})$.

2.4.2. Organic acids extraction and analysis. Organic acids were determined using ultra-fast liquid chromatography coupled to a photodiode array detector (UFLC-PDA). Samples $(\sim 2 \mathrm{~g})$ were extracted by stirring with $25 \mathrm{~mL}$ of meta-phosphoric acid $\left(25^{\circ} \mathrm{C}\right.$ at $150 \mathrm{rpm}$ ) for $45 \mathrm{~min}$ and subsequently filtered through Whatman No. 4 paper. Before analysis, the sample was filtered through $0.2 \mu \mathrm{m}$ nylon filters (Barros, Pereira, Ferreira, 2013). The analysis was performed using a Shimadzu 20A series UFLC (Shimadzu Corporation, Kyoto, Japan). Separation was achieved on a SphereClone (Phenomenex, Torrance, CA, USA) reverse phase $\mathrm{C}_{18}$ column $(5 \mu \mathrm{m}, 250 \mathrm{~mm} \times 4.6 \mathrm{~mm}$ i.d. $)$ 
thermostatted at $35^{\circ} \mathrm{C}$. The elution was performed with sulphuric acid (3.6 mM) using a flow rate of $0.8 \mathrm{~mL} / \mathrm{min}$. Detection was carried out in a PDA, using 215 and $245 \mathrm{~nm}$ (for ascorbic acid) as preferred wavelengths. The organic acids found were quantified by comparison of the area of their peaks recorded at 215 and $245 \mathrm{~nm}$ with calibration curves obtained from commercial standards of each compound: ascorbic acid $\left(\mathrm{y}=8 \mathrm{E}+07 \mathrm{x}+55079 ; \quad R^{2}=1\right) ; \quad$ citric $\quad\left(\mathrm{y}=1 \mathrm{E}+06 \mathrm{x}+4170.6 ; \quad R^{2}=1\right) ; \quad$ fumaric $\quad$ acid $\left(\mathrm{y}=172760 \mathrm{x}+52193 ; R^{2}=0.999\right) ;$ malic acid $\left(\mathrm{y}=952269 \mathrm{x}+17803 ; R^{2}=1\right) ;$ oxalic acid $\left(\mathrm{y}=1 \mathrm{E}+07 \mathrm{x}+96178 ; R^{2}=0.999\right) ;$ quinic acid $\left(\mathrm{y}=601768 \mathrm{x}+8853.2 ; R^{2}=1\right)$. The results were expressed in g per $100 \mathrm{~g}$ of dry weight (dw).

2.4.3. Phenolic compounds extraction and analysis. The previously described methanolic extract and infusion were dissolved in water:methanol $(80: 20, v / v)$ and water, respectively (final concentration $1 \mathrm{mg} / \mathrm{mL}$ ) and analysed using a HewlettPackard 1100 chromatograph (Hewlett-Packard 1100, Agilent Technologies, Santa Clara, CA, US) with a quaternary pump and a diode array detector (DAD) coupled to an HP Chem Station (rev. A.05.04) data-processing station. A Waters Spherisorb S3 ODS$2 \mathrm{C}_{18}, 3 \mu \mathrm{m}(4.6 \mathrm{~mm} \times 150 \mathrm{~mm})$ column thermostatted at $35^{\circ} \mathrm{C}$ was used. The solvents used were: (A) $0.1 \%$ formic acid in water, (B) acetonitrile. The elution gradient established was isocratic $15 \%$ for $5 \mathrm{~min}, 15 \%$ B to $20 \%$ B over $5 \mathrm{~min}, 20-25 \%$ B over $10 \mathrm{~min}, 25-35 \%$ B over $10 \mathrm{~min}, 35-50 \%$ for $10 \mathrm{~min}$, and re-equilibration of the column, using a flow rate of $0.5 \mathrm{~mL} / \mathrm{min}$. Double online detection was carried out in the DAD using $280 \mathrm{~nm}$ and $370 \mathrm{~nm}$ as preferred wavelengths and in a mass spectrometer (MS) connected to HPLC system via the DAD cell outlet.

MS detection was performed in an API 3200 Qtrap (Applied Biosystems, Darmstadt, Germany) equipped with an ESI source and a triple quadrupole-ion trap mass analyzer 
that was controlled by the Analyst 5.1 software. Zero grade air served as the nebulizer gas (30 psi) and turbo gas for solvent drying (400 $\left.{ }^{\circ} \mathrm{C}, 40 \mathrm{psi}\right)$. Nitrogen served as the curtain (20 psi) and collision gas (medium). The quadrupols were set at unit resolution. The ion spray voltage was set at $-4500 \mathrm{~V}$ in the negative mode. The MS detector was programmed for recording in two consecutive modes: Enhanced MS (EMS) and enhanced product ion (EPI) analysis. EMS was employed to show full scan spectra, so as to obtain an overview of all of the ions in sample. Settings used were: declustering potential (DP) $-450 \mathrm{~V}$, entrance potential (EP) $-6 \mathrm{~V}$, collision energy (CE) -10V. EPI mode was performed in order to obtain the fragmentation pattern of the parent ion(s) in the previous scan using the following parameters: DP $-50 \mathrm{~V}, \mathrm{EP}-6 \mathrm{~V}, \mathrm{CE}-25 \mathrm{~V}$, and collision energy spread (CES) $0 \mathrm{~V}$. Spectra were recorded in negative ion mode between $m / z 100$ and 1000.

The phenolic compounds present in the samples were characterised according to their UV and mass spectra and retention times compared with standards when available. For the quantitative analysis of phenolic compounds, a 5-level calibration curve was obtained by injection of known concentrations $(2.5-100 \mu \mathrm{g} / \mathrm{mL})$ of different standards compounds: $p$-coumaric $\left(\mathrm{y}=884.6 \mathrm{x}+184.49 ; R^{2}=0.999\right)$; ferulic acid $(\mathrm{y}=505.97 \mathrm{x}-64.578$; $\left.R^{2}=0.999\right)$; isorahmetin-3-O-rutinoside $\left(\mathrm{y}=327.42 \mathrm{x}+313.78 ; R^{2}=0.999\right)$; luteolin-6- $C$ glucoside $\left(\mathrm{y}=508.54 \mathrm{x}-152.82 ; R^{2}=0.997\right) ;$ luteolin-7- $O$-glucoside $(\mathrm{y}=80.829 \mathrm{x}-21.291$; $\left.R^{2}=0.999\right) ; \quad$ kaempferol-3-O-glucoside $\quad\left(\mathrm{y}=288.55 \mathrm{x}-4.05 ; \quad R^{2}=1\right) ; \quad$ kaempferol-3-O rutinoside $\left(\mathrm{y}=239.16 \mathrm{x}-10.587 ; \quad R^{2}=1\right) ;$ quercetin-3- $O$-glucoside $\quad(\mathrm{y}=253.52 \mathrm{x}-11.615$; $\left.R^{2}=0.999\right)$ and quercetin-3-O-rutinoside $\left(\mathrm{y}=281.98 \mathrm{x}-0.3459 ; R^{2}=1\right)$. The results were expressed in mg per $100 \mathrm{~g}$ of dry weight (dw).

\subsection{Chemical composition in lypophilic compounds}


2.5.1. Fatty acids. Fatty acids were determined by gas-liquid chromatography with flame ionization detection (GC-FID)/capillary column, after trans-esterification procedure. Fatty acids (obtained after Soxhlet extraction) were methylated with $5 \mathrm{~mL}$ of methanol:sulphuric acid:toluene 2:1:1 (v:v:v), during at least $12 \mathrm{~h}$ in a bath at $50{ }^{\circ} \mathrm{C}$ and $160 \mathrm{rpm}$; then $3 \mathrm{~mL}$ of deionised water were added, to obtain phase separation; the FAME were recovered with $3 \mathrm{ml}$ of diethyl ether by shaking in vortex, and the upper phase was passed through a micro-column of sodium sulphate anhydrous, in order to eliminate the water; the sample was recovered in a vial with Teflon, and before injection the sample was filtered with $0.2 \mu \mathrm{m}$ nylon filter from Whatman (Pinela et al., 2012). The analysis was carried out with a DANI model GC 1000 instrument equipped with a split/splitless injector, a flame ionization detector (FID at $260{ }^{\circ} \mathrm{C}$ ) and a MachereyNagel (Düren, Germany) column $\quad(50 \% \quad$ cyanopropyl-methyl-50\% phenylmethylpolysiloxane, $30 \mathrm{~m} \times 0.32 \mathrm{~mm}$ i.d. $\times 0.25 \mu \mathrm{m} \mathrm{d}$ ). The oven temperature program was as follows: the initial temperature of the column was $50^{\circ} \mathrm{C}$, held for $2 \mathrm{~min}$, then a $30{ }^{\circ} \mathrm{C} / \min$ ramp to $125^{\circ} \mathrm{C}, 5{ }^{\circ} \mathrm{C} / \mathrm{min}$ ramp to $160{ }^{\circ} \mathrm{C}, 20^{\circ} \mathrm{C} / \min$ ramp to $180{ }^{\circ} \mathrm{C}$, $3{ }^{\circ} \mathrm{C} / \mathrm{min}$ ramp to $200{ }^{\circ} \mathrm{C}, 20{ }^{\circ} \mathrm{C} / \mathrm{min}$ ramp to $220^{\circ} \mathrm{C}$ and held for $15 \mathrm{~min}$. The carrier gas (hydrogen) flow-rate was $4.0 \mathrm{~mL} / \mathrm{min}(0.61 \mathrm{bar})$, measured at $50{ }^{\circ} \mathrm{C}$. Split injection (1:40) was carried out at $250^{\circ} \mathrm{C}$. Fatty acid identification was made by comparing the relative retention times of FAME peaks from samples with standards. The results were recorded and processed using the CSW 1.7 Software (DataApex 1.7) and expressed in relative percentage of each fatty acid.

2.5.2. Tocopherols. Tocopherols were determined by HPLC (equipment described above), and a fluorescence detector (FP-2020; Jasco). BHT solution in hexane (10 $\mathrm{mg} / \mathrm{mL} ; 100 \mu \mathrm{L}$ ) and IS solution in hexane (tocol; $50 \mu \mathrm{g} / \mathrm{mL} ; 400 \mu \mathrm{L}$ ) were added to the 
sample prior to the extraction procedure. The samples $(\sim 500 \mathrm{mg})$ were homogenized with methanol $(4 \mathrm{~mL})$ by vortex mixing $(1 \mathrm{~min})$. Subsequently, hexane $(4 \mathrm{~mL})$ was added and again vortex mixed for $1 \mathrm{~min}$. After that, saturated $\mathrm{NaCl}$ aqueous solution (2 $\mathrm{mL}$ ) was added, the mixture was homogenized (1 min), centrifuged (5 min, 4000g) and the clear upper layer was carefully transferred to a vial. The sample was re-extracted twice with hexane. The combined extracts were taken to dryness under a nitrogen stream, redissolved in $2 \mathrm{~mL}$ of n-hexane, dehydrated with anhydrous sodium sulphate, filtered through $0.2 \mu \mathrm{m}$ nylon filters from Whatman, transferred into a dark injection vial prior to the analysis (Pinela et al., 2012). The fluorescence detector was programmed for excitation at $290 \mathrm{~nm}$ and emission at $330 \mathrm{~nm}$. The chromatographic separation was achieved with a Polyamide II $(250 \mathrm{~mm} \times 4.6 \mathrm{~mm}$ i.d.) normal-phase column from YMC Waters operating at $30^{\circ} \mathrm{C}$. The mobile phase used was a mixture of n-hexane and ethyl acetate $(70: 30, v / v)$ at a flow rate of $1 \mathrm{~mL} / \mathrm{min}$, and the injection volume was $20 \mu \mathrm{L}$. The compounds were identified by chromatographic comparisons with authentic standards. Quantification was based on calibration curves obtained from commercial standards of each compound using the IS methodology. The results were expressed in mg per $100 \mathrm{~g}$ of dry weight (dw).

\subsection{Statistical analysis}

Three samples were used and all the assays were carried out in triplicate. The results are expressed as mean values and standard deviation (SD). The results were analyzed using one-way analysis of variance (ANOVA) followed by Tukey's HSD Test with $\alpha=0.05$. This treatment was carried out using SPSS v. 18.0 program.

\section{Results and Discussion}




\subsection{Evaluation of bioactive properties}

The results obtained in the evaluation of the bioactive properties (antioxidant and antitumour activities, and hepatotoxicity) of the infusion and the methanolic extract of C. ambrosioides are given in Table 1. The infusion gave higher DPPH scavenging activity and $\beta$-carotene bleaching and TBARS inhibitions than the methanolic extract. The latter revealed higher reducing power. The essential oil extracted from the leaves of C. ambrosioides (Kumar, Kumar, Dubey, \& Tripathi, 2007) was also reported to show powerful antioxidant activity. To the best of our knowledge, no reports are available on the infusion or methanolic extract of the aforementioned plant.

The effects of $C$. ambrosioides methanolic extract and infusion on the growth of five human tumour cell lines (MCF-7, NCI-H460, HCT-15, HeLa and HepG2), represented as the concentrations that caused $50 \%$ of cell growth inhibition $\left(\mathrm{GI}_{50}\right)$, are also summarized in Table 1. The infusion of C. ambrosioides did not show any antitumour potential; however, the methanolic extract presented some activity on HCT-15, HeLa and HepG2 cell lines. It should be highlighted that no hepatotoxicity in non-tumour cells was observed for any of the samples $\left(\mathrm{GI}_{50}>400 \mu \mathrm{g} / \mathrm{mL}\right)$. Trolox and ellipticine were used as positive controls of antioxidant and antitumour activities evaluation assays, respectively, but comparison with the samples should be avoided, because they are individual compounds and not mixtures.

\subsection{Chemical composition in hydrophilic compounds}

The chemical composition of the samples in sugars and organic acids was also analyzed and the results are shown in Table 2. The sugars found were fructose, glucose, sucrose and trehalose, sucrose being the most abundant. 
Oxalic, quinic, malic, ascorbic, citric and fumaric acids were also identified and quantified (Table 2), being oxalic acid the most abundant organic acid. Some organic acids (e.g., citric acid) have been reported as having antioxidant capacity (Hraš, Halodin, Knez, \& Bauman, 2000).

Phenolic compounds found in C. ambrosioides are presented in Table 3 and Figure 1. Thirty-five compounds were detected, eight of which were phenolic acid derivatives (hydroxycinnamic acid derivatives). Among them, five compounds (peaks 1-3, 5 and 9) were $p$-coumaric acid derivatives identified according to their UV spectra and pseudomolecular ion. Peak 9 was identified as trans $p$-coumaric acid by comparison of its UV spectrum $\left(\lambda_{\max } 312 \mathrm{~nm}\right)$ and retention time with a commercial standard. Peak 1 was identified as a $p$-coumaroyl pentoside acid according to its pseudomolecular $[\mathrm{M}-\mathrm{H}]^{-}$ ion $(\mathrm{m} / \mathrm{z}$ at 295$)$ and the release of fragments at $\mathrm{m} / z 163$ [p-coumaric acid-H] $]^{-}(-132 \mathrm{mu}$, pentose) and $\mathrm{m} / z 119$ (loss of $132+44 \mathrm{mu}$, pentose $+\mathrm{CO}_{2}$ ). Peaks 2, 3 and 5 presented pseudomolecular ions $[\mathrm{M}-\mathrm{H}]^{-}$at $\mathrm{m} / \mathrm{z} 287$ and 387 releasing the same fragment ions at $\mathrm{m} / \mathrm{z} 163$ and 119, which allowed assigning them to $p$-coumaroyl acid derivatives, although their precise identities could not be established. The other three phenolic acid derivatives were identified as ferulic acid derivatives based on the observation of the ions at $m / z 193$ ([ferulic acid-H] $\left.]^{-}\right)$and 149 ([ferulic acid- $\left.\left.\mathrm{CO}_{2}-\mathrm{H}\right]^{-}\right)$. Peak 14 could be identified as free ferulic acid by comparison of its UV spectrum $\left(\lambda_{\max } 326 \mathrm{~nm}\right)$ and retention time with a commercial standard. Peak 4 was associated to a feruloyl pentoside acid based on its molecular ion fragmentation pattern similar to peak 1 , whereas no precise identity could be established for peak 6 .

The remaining phenolic compounds corresponded to flavone and flavonol derivatives, most of them derived from quercetin ( $\lambda_{\max }$ around $354 \mathrm{~nm}$ and $\mathrm{MS}^{2}$ fragment at $\mathrm{m} / \mathrm{z} 301$; 
12 compounds) and kaempferol ( $\lambda_{\max }$ around $346 \mathrm{~nm}$ and $\mathrm{MS}^{2}$ fragment at $m / z 285 ; 11$ compounds) (Table 3). Quercetin 3-O-rutinoside (peak 17), quercetin 3-O-glucoside (peak 21) and kaempferol 3-O-rutinoside (peak 24) were positively identified according to their retention, mass and UV-vis characteristics by comparison with commercial standards.

Peak $10\left([\mathrm{M}-\mathrm{H}]^{-}\right.$at $\left.\mathrm{m} / \mathrm{z} 609\right)$ could be interpreted as a quercetin $O$-diglycosides in which each of the sugar moieties are located at different positions on the aglycone, owing to the observation of fragments derived from the loss of each sugar residue. However, it might also be rationalised as a quercetin $O$-rhamnosyl-glucoside, in which the fragment at $m / z 447$ would correspond to the loss of the terminal glucose of the dissacharide, whereas that at $\mathrm{m} / \mathrm{z} 463$ might be rationalised as produced by an internal rearrangement in the sugar moieties following the loss of the internal dehydrated glucose/pentose and further linkage of the terminal rhamnose to the aglycone (Ma, Cuyckens, Heuvel, \& Claeys, 2001). In that case, the greater abundance of the $\mathrm{Y}_{0}$ ion $(\mathrm{m} / \mathrm{z}$ at 301 ; aglycone $)$ than $\mathrm{Y}_{1}$ ion $(\mathrm{m} / \mathrm{z}$ at 447 ; breakdown of the interglycosidic linkage) might support the existence of a 1,2 interglycosidic linkage (Cuyckens, Rozenberg, Hoffmann, \& Claeys, 2001), which allow the identification of peak 10 as quercetin 3-O-neohesperidose.

Peaks 15 and 20, both with a pseudo molecular ion $[\mathrm{M}-\mathrm{H}]^{-}$at $\mathrm{m} / \mathrm{z} 579$ releasing fragments at $m / z 447(-132 \mathrm{mu}$; pentiosyl residue) and 301 (-132-146 mu; loss of pentosyl+ rhamnosyl residues), could be assigned as quercetin $O$-rhamnosyl-pentosides in which the pentose is the terminal unit owing to the lack of a fragment at $\mathrm{m} / \mathrm{z} 433$, which should result from the loss of the rhamnose residue if both sugars were located at different positions on the aglycone. The observation that $Y_{0}>Y_{1}$ ion in the case of peak 20 might point to a 1,2 interglycosidic linkage, whereas a 1,6 linkage might exist in peak 15 where $\mathrm{Y}_{1}>\mathrm{Y}_{0}$ (Cuyckens et al., 2001). Peaks 29 and 30, both possessing a 
pseudo molecular ion [M-H] ${ }^{-}$at $m / z 623$ and releasing fragments at $m / z 447$ (-176 mu; loss of a glucuronyl residue) and 301 (-176-146 mu; loss of glucuronyl+rhamnosyl residues) should correspond to quercetin $O$-rhamnosyl-glucuronides. Furthermore, as mentioned above, in peak 30 a 1,2 interglycosidic linkage could be observation $\left(\mathrm{Y}_{0}>\right.$ $\left.\mathrm{Y}_{1}\right)$, whereas a 1,6 linkage might exist in peak $29\left(\mathrm{Y}_{1}>\mathrm{Y}_{0}\right)$. Peak 34 can be assigned to an acetyl derivative of peak 30 owing to its pseudomolecular ion ([M-H] at $m / z 665) 42$ mu higher than that peak.

The pseudomolecular ion of peak $19\left([\mathrm{M}-\mathrm{H}]^{-}\right.$at $\left.\mathrm{m} / \mathrm{z} 593\right)$ is coherent with a quercetin derivative bearing two rhamnosyl residues. In principle, it can be supposed that each sugar is located at different positions on the aglycone as suggested by the formation of a fragment ion at $\mathrm{m} / \mathrm{z} 447$ from the loss of one of the rhamnosyl moieties, although the possibility that they constituted a disaccharide cannot be disregarded, either.

Peak $11\left([\mathrm{M}-\mathrm{H}]^{-}\right.$at $\left.m / z 741\right)$ can be assigned to a quercetin derivative bearing pentosyl, rhamnosyl and hexosyl residues, based on the loss of $440 \mathrm{u}(132+146+162 \mathrm{u})$ to yield the corresponding aglycone $(\mathrm{m} / \mathrm{z}$ at 301 , quercetin). The fact that the three moieties were lost simultaneously suggested that they might constitute a trisaccharide $O$-linked to the aglycone. Similarly, peak 12 would be associated to a quercetin $O$-disaccharide consisting of a pentose and a hexose.

Peak $8\left([\mathrm{M}-\mathrm{H}]^{-}\right.$at $m / z$ 755) would correspond to a quercetin derivative possessing two rhamnosyl and one glucosyl moieties. The observation of a fragment at $\mathrm{m} / \mathrm{z} 609$ from the lost of a rhamnosyl residue (-146 mu) points to this sugar is located on the aglycone in a position different to the other two sugars that should constitute a disaccharide. The presence of quercetin 3-O-rutinoside (peak 17) as majority flavonoid in the plant might suggest that peak 8 could be quercetin 3-O-rutinoside- $O$-rhamnoside. 
Similar reasoning as for the quercetin derivatives has been applied for assigning the identities of kaempferol (peaks 13, 16, 18, 22, 23, 25, 26, 31, 32 and 35) and isorhamnetin derivatives (peaks 27, 28 and 33), as indicated in Table 3.

Finally, peak $7\left([\mathrm{M}-\mathrm{H}]^{-}\right.$at $\left.m / z 579\right)$ was assigned to a flavone, luteolin $C$-hexoside- $O$ pentoside, based on its fragmentation. Thus, the ion at $\mathrm{m} / \mathrm{z} 447$ could be interpreted as the loss of the pentosyl moiety $(-132 \mathrm{mu})$ and a fragment of $120 \mathrm{mu}$ characteristic of the cleavage of pyran ring in the more strongly linked $C$-hexoses, whereas the ion at $\mathrm{m} / \mathrm{z}$ 417 might correspond to the loss of the hexosyl moiety and a fragment of $30 \mathrm{mu}$ resulting from $\mathrm{CH}_{2} \mathrm{O}$ functional group of the hexose, also observed in the case of $C$ hexoses (Abad-Garcia, Garmon-Lobato, Berrueta, Gallo, \& Vicente, 2008). The fragments ions at $\mathrm{m} / \mathrm{z} 447$ and 285 would correspond to the respective losses of the pentosyl and hexosyl moieties, respectively.

Flavonoids were the major phenolic compounds present in this sample $(768 \mathrm{mg} / 100 \mathrm{~g}$ $\mathrm{dw})$, being quercetin (46.98\%) and kaempferol derivatives (45.91\%) the most abundant. Quercetin 3-O-rutinoside was the compound found in the highest amount (205 mg/100 $\mathrm{g} \mathrm{dw}$, peak 17), followed by kaempferol dirhamnoside- $O$-pentoside $(96 \mathrm{mg} / 100 \mathrm{~g} \mathrm{dw}$, peak 25). Phenolic acids were $6.58 \%$ of the total phenolic compounds in this sample and trans $p$-coumaric acid was the most abundant one $(25.65 \mathrm{mg} / 100 \mathrm{~g} \mathrm{dw}$, peak 9). Herbal infusions are frequently used in traditional medicine due to their beneficial activities and among their constituents, special relevance has been given to phenolic compounds, which often exhibit high antioxidant capacity being able to counteract oxidative stress (Mejía, Songa, Hecka, Vinicio, \& Ramírez-Mares, 2010; Pereira, Marcias, Perez, Marin \& Cardoso, 2013). They act as antioxidants through various mechanisms, including hydrogen donating reactions, metal chelation, and up-regulation or protection of antioxidant defenses (e.g. intracellular glutathione levels) (Pereira et al., 
2013). In particular, C. ambrosioides infusion is a rich source of diverse polyphenols that could contribute to the mentioned activity.

\subsection{Chemical composition in lipophilic compounds}

The results of lipophilic compounds (fatty acids and tocopherols) are shown in Table 4. Up to 26 fatty acids were identified and quantified. Polyunsaturated fatty acids (PUFA) predominated over saturated fatty acids (SFA) and monounsaturated fatty acids (MUFA). $\alpha$-Linolenic (C18:3n3; 48.54\%) and linoleic (C18:2n6; 19.23\%) acids contribute to the high levels of PUFA observed (68.44\%). Linoleic acid is the most prominent PUFA in the Western diet and previous studies showed health benefits under the prevention of cancer diseases (Whelan, 2008).

$\alpha$-Tocopherol was, by far, the most abundant tocopherol in C. ambrosioides (199.37 $\mathrm{mg} / 100 \mathrm{~g} \mathrm{dw}$ from a total tocopherols amount of $202.34 \mathrm{mg} / 100 \mathrm{~g} \mathrm{dw}$; Table 4). Tocopherols are very important natural antioxidants in plant foods, especially those that are rich in PUFA. Their effectiveness as antioxidants depends not only on their reactivity against harmful radicals, but also the relatively stable nature of his radical due to relocation of the unpaired electron on the ring cromanol (Kagan et al., 2003).

Overall, C. ambrosioides infusion revealed, in general, higher antioxidant activity, while the methanolic extract was the only one showing antitumour effects against colon, cervical and hepatocellular carcinoma cell lines. Neither the infusion nor the extract reveal toxicity for non-tumour cells. Bioactive compounds such as some sugars and organic acids, phenolic compounds, unsaturated fatty acids and tocopherols were identified and quantified in C. ambrosioides. As far as we know, this is the first detailed 
chemical characterization of $C$. ambrosioides and bioactivity evaluation of its methanolic extract and infusion.

\section{Acknowledgements}

The authors are grateful to Fundação para a Ciência e a Tecnologia (FCT, Portugal) for financial support to CIMO (strategic project PEst-OE/AGR/UI0690/2011). R.C. Calhelha and L. Barros also thank to FCT, POPH-QREN and FSE for their grants (SFRH/BPD/ BPD/68344/2010 and SFRH/BPD/4609/2008, respectively). The GIPUSAL is financially supported by the Spanish Government through the ConsoliderIngenio 2010 Programme (FUN-C-FOOD, CSD2007-00063). M. Dueñas thanks to the Programa Ramón y Cajal for a contract. 


\section{References}

Abad-Garcia, B., Garmon-Lobato, S, Berrueta, L.A., Gallo B., \& Vicente F. (2008) New features on the fragmentation and differentiation of C-glycosidic flavone isomers by positive electrospray ionization and triple quadrupole mass spectrometry. Rapid Commun Mass Spectrom, 22, 1834-1842.

Abreu, R.M.V., Ferreira, I.C.F.R., Calhelha, R.C., Lima, R.T., Vasconcelos, M.H., Adega, F., Chaves, R., \& Queiroz, M.J.R.P. (2011). Anti-hepatocellular carcinoma activity using human HepG2 cells and hepatotoxicity of 6-substituted methyl 3aminothieno[3,2-b]pyridine-2-carboxylate derivatives: In vitro evaluation, cell cycle analysis and QSAR studies. European Journal of Medicinal Chemistry, 46, $5800-5806$.

Barros, L., Pereira, C., \& Ferreira, I.C.F.R. (2013). Optimized analysis of organic acids in edible mushrooms from Portugal by ultra fast liquid chromatography and photodiode array detection. Food Analytical Methods, 6, 309-316.

Carvalho, A.M. (2010). Plantas y sabiduría popular del Parque Natural de Montesinho. Un estudio etnobotánico en Portugal. Biblioteca de Ciencias, vol. 35. Consejo Superior de Investigaciones Científicas, Madrid.

Cruz, G.V.B., Pereira P.V.S., Patrício, F.J., Costa, G.C., Sousa, S.M., Frazão, J.B., Aragão-Filho, W.C., Maciel, M.C.G., Silva, L.A., Amaral, F.M.M., Barroqueiro, E.S.B., Guerra, R.N.M., \& Nascimento, F.R.F. (2007). Increase of cellular recruitment, phagocytosis ability and nitric oxide production induced by hydroalcoholic extract from Chenopodium ambrosioides leaves. Journal of Ethnopharmacology, 111, 148-154. 
Cuyckens, F., Rozenberg, R., Hoffmann, E., \& Claeys, M. (2001). Structure characterization of flavonoid O-diglycosides by positive and negative nanoelectrospray ionization ion trap mass spectrometry. Journal of Mass Spectrometry, $36,1203-1210$.

Guimarães, R., Barros, L., Dueñas, M., Calhelha, R.C., Carvalho, A.M., Santos-Buelga, C., Queiroz, M.J.R.P., \& Ferreira, I.C.F.R. (2013). Nutrients, phytochemicals and bioactivity of wild Roman chamomile: a comparison between the herb and its preparations. Food Chemistry, 136, 718-725.

Halliwell, B. (2012). Free radicals and antioxidants: updating a personal view. Nutrition Reviews, 70, 257-265

Hraš, A.R., Halodin, M., Knez, Z., \& Bauman, D. (2000). Comparison of antioxidative and synergistic effects of rosemary extract with $\alpha$-tocopherol, ascorbyl palmitate and citric acid in sunflower oil. Food Chemistry, 71, 229-233.

Kagan, V.E., Kuzmenko, A.I., Shvedova, A.A., Kisin, E.R., Li, R., Martin, I., Quinn, P.J., Tyurin, V.A., Tyurina, Y.Y., \& Yalowich, J.C. (2003). Direct evidence for recycling of myeloperoxidase-catalyzed phenoxyl radicals of a vitamin E homologue, 2,2,5,7,8-pentamethyl-6-hydroxy chromane, by ascorbate/dihydrolipoate in living HL-60 cells. Biochimica et Biophysica Acta, $1620,72-84$

Kamel, E.G., El-Emam, M.A., Mahmoud, S.S.M, Fouda, F.M., \& Bayaumy, F.E. (2011). Parasitological and biochemical parameters in Schistosoma mansoniinfected mice treated with methanol extract from the plants Chenopodium 
ambrosioides, Conyza dioscorides and Sesbania sesban. Parasitology International, 60, 388-392.

Kumar, R., Kumar, M.A., Dubey, N.K., \& Tripathi, Y.B. (2007) Evaluation of Chenopodium ambroisioides oil as a potential source of antifungal, antiaflatoxigenic and antioxidant activity. International Journal of Food Microbiology, 115, 159-164.

Ma, Y.-L., Cuyckens, F., Heuvel, H.V., \& Claeys, M. (2001). Mass Spectrometric Methods for the Characterisation and Differentiation of Isomeric O-diglycosyl Flavonoids. Phytochemical Analysis, 12, 159-165.

Mejía, E.G, Songa, Y.S., Hecka, C.I., \& Ramírez-Mares, M.V. (2010). Yerba mate tea (Ilex paraguariensis): Phenolics, antioxidant capacity and in vitro inhibition of colon cancer cell proliferation. Journal of Functional Foods, 2, 23-34.

Nascimento, F.R.F., Cruz, G.V.B., Pereira, P.V.S., Maciel, M.C.G., Silva, L.A., Azevedo, A.P.S., Barroqueiro, E.S.B., \& Guerra, R.N.M. (2006). Ascitic and solid Ehrlich inhibition by Chenopodium ambrosioides L. treatment. Life science, 78 , $2650-2653$

Pereira O.R., Marcias, R.I.R., Perez, M.J., Marin, J.J.G., \& Cardoso, S.M. (2013). Protective effects of phenolic constituents from Cytisus multiflorus, Lamium album L. and Thymus citriodorus on liver cells. Journal of Functional Foods, in press, doi.org/10.1016/j.jff.2013.03.014.

Pinela, J., Barros, L., Dueñas, M., Carvalho, A.M., Santos-Buelga, C., \& Ferreira, I.C.F.R. (2012). Antioxidant activity, ascorbic acid, phenolic compounds and sugars of wild and commercial Tuberaria lignosa samples: effects of drying and oral preparation methods. Food Chemistry, 135, 1028-1035. 
Ramarathnam, N., Osawa, T., Ochi, H., \& Kawakishi, S. (1995). The contribution of plant food antioxidants to human health. Trends in Food Science \& Technology, 6, $75-82$.

Rosenfeldt, F., Wilson, M., Lee, G., Kure, C., Ou, R., Braun,L., \& Haan, J. (2013). Oxidative stress in surgery in an ageing population: Pathophysiology and therapy. Experimental Gerontology, 48, 45-54.

Skerget, M., Kotnik, P., Hadolin, M., Hras, A.R., Simonic, M., \& Knez, Z. (2005). Phenols, proanthocyanidins, flavones and flavonols in some plant materials and their antioxidant activities. Food Chemistry, 89, 191-198.

Valko, M., Leibfritz D., Moncol, J., Cronin, M.T., Mazur, M., \& Telser, J. (2007). Free radicals and antioxidants in normal physiological functions and human disease. International Journal of Biochemistry and Cell Biology, 39, 44-84.

Whelan, J. (2008). The health implications of changing linoleic acid intakes. Prostaglandins, Leukotrienes and Essential Fatty Acids, 79, 165-167. 
Table 1. Bioactive properties of the methanolic extract and infusion of wild Chenopodium ambrosioides.

\begin{tabular}{|c|c|c|c|}
\hline & Methanolic extract & Infusion & Positive control* \\
\hline \multicolumn{4}{|l|}{ Antioxidant activity } \\
\hline $\begin{array}{l}\text { DPPH scavenging activity } \\
\left(\mathrm{EC}_{50}, \mathrm{mg} / \mathrm{mL}\right)\end{array}$ & $0.62 \pm 0.08^{\mathrm{a}}$ & $0.49 \pm 0.02^{\mathrm{b}}$ & $0.04 \pm 0.00$ \\
\hline $\begin{array}{l}\text { Reducing power } \\
\left(\mathrm{EC}_{50}, \mathrm{mg} / \mathrm{mL}\right)\end{array}$ & $0.47 \pm 0.03^{b}$ & $0.65 \pm 0.01^{\mathrm{a}}$ & $0.03 \pm 0.00$ \\
\hline $\begin{array}{l}\beta \text {-carotene bleaching inhibition } \\
\left(\mathrm{EC}_{50}, \mathrm{mg} / \mathrm{mL}\right)\end{array}$ & $2.53 \pm 0.04^{\mathrm{a}}$ & $2.32 \pm 0.37^{\mathrm{b}}$ & $0.003 \pm 0.00$ \\
\hline $\begin{array}{l}\text { TBARS inhibition } \\
\left(\mathrm{EC}_{50}, \mathrm{mg} / \mathrm{mL}\right)\end{array}$ & $0.70 \pm 0.29^{\mathrm{a}}$ & $0.25 \pm 0.01^{\mathrm{b}}$ & $0.004 \pm 0.00$ \\
\hline \multicolumn{4}{|l|}{ Antitumour activity } \\
\hline $\begin{array}{l}\text { MCF-7 (breast carcinoma) } \\
\left(\mathrm{GI}_{50}, \mu \mathrm{g} / \mathrm{mL}\right)\end{array}$ & $>400$ & $>400$ & $0.91 \pm 0.04$ \\
\hline $\begin{array}{l}\text { NCI-H460 (non-small cell lung cancer) } \\
\left(\mathrm{GI}_{50}, \mu \mathrm{g} / \mathrm{mL}\right)\end{array}$ & $>400$ & $>400$ & $1.42 \pm 0.00$ \\
\hline $\begin{array}{l}\text { HCT-15 (colon carcinoma) } \\
\left(\mathrm{GI}_{50}, \mu \mathrm{g} / \mathrm{mL}\right)\end{array}$ & $318.75 \pm 13.21$ & $>400$ & $1.91 \pm 0.06$ \\
\hline $\begin{array}{l}\text { HeLa (cervical carcinoma) } \\
\left(\mathrm{GI}_{50}, \mu \mathrm{g} / \mathrm{mL}\right)\end{array}$ & $264.17 \pm 10.57$ & $>400$ & $1.14 \pm 0.21$ \\
\hline $\begin{array}{l}\text { HepG2 (hepatocellular carcinoma) } \\
\left(\mathrm{GI}_{50}, \mu \mathrm{g} / \mathrm{mL}\right)\end{array}$ & $287.43 \pm 21.99$ & $>400$ & $3.22 \pm 0.67$ \\
\hline $\begin{array}{l}\text { Hepatotoxicity } \\
\text { PLP2 }\left(\mathrm{GI}_{50}, \mu \mathrm{g} / \mathrm{mL}\right)\end{array}$ & $>400$ & $>400$ & $2.06 \pm 0.03$ \\
\hline
\end{tabular}

*Trolox and ellipticine for antioxidant and antitumour activity assays, respectively. $\mathrm{EC}_{50}$ values correspond to the sample concentration achieving 50\% of antioxidant activity or 0.5 of absorbance in reducing power assay. $\mathrm{GI}_{50}$ values correspond to the sample concentration achieving $50 \%$ of growth inhibition in human tumour cell lines or in liver primary culture PLP2. In each row different letters mean significant differences $(\mathrm{p}<0.05)$. 
Table 2. Chemical composition in hydrophilic compounds- sugars and organic acids- of wild Chenopodium ambrosioides.

\begin{tabular}{llll}
\hline Free sugars & $\mathrm{g} / 100 \mathrm{~g} \mathrm{dw}$ & Organic acids & $\mathrm{g} / 100 \mathrm{~g} \mathrm{dw}$ \\
\hline Fructose & $0.24 \pm 0.01$ & Oxalic acid & $5.64 \pm 0.30$ \\
Glucose & $0.46 \pm 0.01$ & Quinic acid & $0.97 \pm 0.14$ \\
Sucrose & $1.43 \pm 0.12$ & Malic acid & $0.67 \pm 0.06$ \\
Trehalose & $0.91 \pm 0.03$ & Ascorbic acid & $0.02 \pm 0.00$ \\
Total sugars & $3.04 \pm 0.07$ & Citric acid & $0.26 \pm 0.01$ \\
& & Fumaric acid & $0.02 \pm 0.00$ \\
& & Total organic acids & $7.58 \pm 0.52$ \\
\hline
\end{tabular}

dw- dry weight. 
Table 3. Retention time (Rt), wavelengths of maximum absorption in the UV-vis region $\left(\lambda_{\max }\right)$, pseudomolecular and $\mathrm{MS}^{2}$ fragment ions (in brackets, relative abundances), identification and quantification of phenolic compounds in wild C. ambrosiodes.

\begin{tabular}{lllllll}
\hline Peak & Rt $(\mathrm{min})$ & $\begin{array}{c}\lambda_{\max } \\
(\mathrm{nm})\end{array}$ & $\begin{array}{l}\text { Molecular ion } \\
{[\mathrm{M}-\mathrm{H}]^{-}(\mathrm{m} / \mathrm{z})}\end{array}$ & $\begin{array}{l}\mathrm{MS}^{2} \\
(\mathrm{~m} / \mathrm{z})\end{array}$ & $\begin{array}{l}\text { Identification } \\
\text { Quantification } \\
(\mathrm{mg} / 100 \mathrm{~g} \mathrm{dw})\end{array}$ \\
\hline 1 & 6.8 & 310 & 295 & $163(100), 119(60)$ & $p$-Coumaroyl pentoside acid & $3.53 \pm 0.50$ \\
2 & 7.1 & 314 & 278 & $163(6), 119(13)$ & $p$-Coumaroyl acid derivative & $9.75 \pm 0.44$ \\
3 & 7.5 & 328 & 387 & $387(100) 207(25), 163(50), 119(37)$ & $p$-Coumaroyl acid derivative & $1.41 \pm 0.09$ \\
4 & 8.2 & 328 & 325 & $193(100), 149(38)$ & Feruloyl pentoside acid & $2.58 \pm 0.27$ \\
5 & 8.8 & 308 & 278 & $163(6), 119(13)$ & $p$-Coumaroyl acid derivative & $1.21 \pm 0.15$ \\
6 & 14.8 & 326 & 473 & $267(27), 193(100)$ & Ferulic acid derivative & $3.51 \pm 0.14$ \\
7 & 15.7 & 332 & 579 & $447(15), 417(7), 327(7), 285(100)$ & Luteolin $C$-hexoside- $O$-pentoside & $2.27 \pm 0.09$ \\
8 & 15.9 & 354 & 755 & $609(2), 301(100)$ & Quercetin 3- $O$-rutinoside-(1 $\rightarrow 2)$ - $O$-rhamnoside & $15.23 \pm 0.41$ \\
9 & 16.4 & 312 & 163 & $119(100)$ & trans $p$-Coumaric acid & $25.65 \pm 0.77$ \\
10 & 16.9 & 356 & 609 & $463(30), 447(33), 301(36)$ & Quercetin 3- $O$-neohesperide & $7.19 \pm 0.32$ \\
11 & 17.2 & 354 & 741 & $301(100)$ & Quercetin $O$-pentosyl-rhamnosyl-hexoside & $27.60 \pm 0.31$ \\
12 & 17.6 & 356 & 595 & $301(100)$ & Quercetin $O$-pentosyl-hexoside & $3.55 \pm 0.46$ \\
13 & 18.1 & 348 & 739 & $285(100)$ & Kaempferol $O$-dirhamnosyl-hexoside & $20.38 \pm 0.74$ \\
14 & 18.3 & 326 & 193 & $149(17), 135(100)$ & Ferulic acid & $6.43 \pm 0.53$ \\
15 & 18.6 & 354 & 579 & $447(100), 301(33)$ & Quercetin $O$-rhamnosyl-pentoside & $8.06 \pm 0.87$ \\
16 & 19.0 & 348 & 739 & $593(83), 431(17), 285(67)$ & Kaempferol dirhamnoside- $O$-hexoside & $4.80 \pm 0.49$ \\
17 & 19.4 & 354 & 609 & $301(100)$ & Quercetin-3- $O$-rutinoside & $204.95 \pm 6.39$ \\
18 & 19.8 & 346 & 725 & $285(100)$ & Kaempferol $O$-pentosyl-rhamnosyl-hexoside & $31.42 \pm 1.36$ \\
19 & 20.2 & 352 & 593 & $447(64), 301(100)$ & Quercetin dirhamnoside & $56.63 \pm 0.35$
\end{tabular}




\begin{tabular}{lllllll}
20 & 20.4 & 354 & 579 & $447(45), 301(100)$ & Quercetin $O$-rhamnosyl-pentoside & $1.22 \pm 0.03$ \\
21 & 20.8 & 350 & 463 & $301(100)$ & Quercetin 3- $O$-glucoside & $12.91 \pm 0.80$ \\
22 & 21.5 & 348 & 563 & $431(53), 285(100)$ & Kaempferol $O$-rhamnosyl-pentoside & $4.93 \pm 0.08$ \\
23 & 22.4 & 344 & 739 & $593(24), 431(24), 285(100)$ & Kaempferol dirhamnoside- $O$-hexoside & $11.31 \pm 0.44$ \\
24 & 23.1 & 348 & 593 & $285(100)$ & Kaempferol 3- $O$-rutinoside & $74.82 \pm 2.29$ \\
25 & 23.5 & 342 & 709 & $563(25), 431(63), 285(100)$ & Kaempferol dirhamnoside- $O$-pentoside & $95.89 \pm 1.64$ \\
26 & 23.9 & 344 & 563 & $431(47), 285(100)$ & Kaempferol $O$-rhamnosyl-pentoside & $36.15 \pm 1.40$ \\
27 & 24.6 & 350 & 607 & $461(50), 315(100)$ & Isorhamnetin dirhamnoside & tr \\
28 & 25.1 & 352 & 593 & $461(80), 315(100)$ & Isorhamnetin $O$-rhamnosyl-pentoside & $1.60 \pm 0.09$ \\
29 & 26.0 & 352 & 623 & $447(50), 301(43)$ & Quercetin $O$-rhamnosyl-glucuronide & $2.48 \pm 0.04$ \\
30 & 26.6 & 352 & 623 & $447(33), 301(51)$ & Quercetin $O$-rhamnosyl-glucuronide & $33.99 \pm 0.28$ \\
31 & 29.6 & 344 & 607 & $459(30), 431(20), 285(50)$ & Kaempferol $O$-rhamnosyl-glucuronide & $6.54 \pm 0.28$ \\
32 & 30.5 & 346 & 607 & $431(100), 285(86)$ & Kaempferol $O$-rhamnosyl-glucuronide & $56.08 \pm 0.35$ \\
33 & 31.2 & 350 & 637 & $461(100), 315(87)$ & Isorhamnetin $O$-rhamnosyl-glucuronide & $0.50 \pm 0.00$ \\
34 & 31.7 & 352 & 665 & $623(14), 447(35), 301(18)$ & Quercetin (acyl)glucuronide- $O$-rhamnoside & $12.53 \pm 0.56$ \\
35 & 35.1 & 344 & 649 & $607(6), 431(42), 285(31)$ & Kaempferol (acyl)glucuronide- $O$-rhamnoside & $35.26 \pm 1.43$ \\
\hline & & & & & Phenolic acids & $54.07 \pm 1.55$ \\
& & & & & Flavonoids & $768.27 \pm 10.70$ \\
& & & & Phenolic compounds & $822.33 \pm 12.25$ \\
\hline
\end{tabular}

dw- dry weight; tr- traces 
Table 4. Chemical composition in lipophilic compounds of wild $\mathrm{Cl}$ ambrosioides.

\begin{tabular}{llll}
\hline Fatty acids & Relative percentage & Fatty acids & Relative percentage \\
\hline C6:0 & $0.10 \pm 0.01$ & $\mathrm{C} 18: 3 \mathrm{n} 3$ & $48.54 \pm 0.13$ \\
$\mathrm{C} 8: 0$ & $0.49 \pm 0.02$ & $\mathrm{C} 20: 0$ & $0.83 \pm 0.00$ \\
$\mathrm{C} 10: 0$ & $0.34 \pm 0.01$ & $\mathrm{C} 20: 1$ & $0.19 \pm 0.01$ \\
$\mathrm{C} 12: 0$ & $0.17 \pm 0.03$ & $\mathrm{C} 20: 2$ & $0.17 \pm 0.03$ \\
$\mathrm{C} 13: 0$ & $0.41 \pm 0.01$ & $\mathrm{C} 20: 3 \mathrm{n} 6$ & $0.12 \pm 0.01$ \\
$\mathrm{C} 14: 0$ & $0.48 \pm 0.02$ & $\mathrm{C} 20: 4 \mathrm{n} 6$ & $0.04 \pm 0.01$ \\
$\mathrm{C} 14: 1$ & $0.47 \pm 0.05$ & $\mathrm{C} 20: 3 \mathrm{n} 3+\mathrm{C} 21: 0$ & $0.29 \pm 0.01$ \\
$\mathrm{C} 15: 0$ & $0.44 \pm 0.02$ & $\mathrm{C} 20: 5 \mathrm{n} 3$ & $0.03 \pm 0.01$ \\
$\mathrm{C} 16: 0$ & $14.16 \pm 0.03$ & $\mathrm{C} 22: 0$ & $1.85 \pm 0.05$ \\
$\mathrm{C} 16: 1$ & $0.14 \pm 0.03$ & $\mathrm{C} 22: 2$ & $0.01 \pm 0.00$ \\
$\mathrm{C} 17: 0$ & $0.32 \pm 0.01$ & $\mathrm{C} 23: 0$ & $0.21 \pm 0.00$ \\
$\mathrm{C} 18: 0$ & $1.57 \pm 0.08$ & $\mathrm{C} 24: 0$ & $2.52 \pm 0.09$ \\
$\mathrm{C} 18: 1 \mathrm{n} 9$ & $6.90 \pm 0.12$ & SFA & $23.87 \pm 0.08$ \\
$\mathrm{C} 18: 2 \mathrm{n} 6$ & $19.23 \pm 0.12$ & MUFA & $7.69 \pm 0.16$ \\
& & $\mathrm{PUFA}$ & $68.44 \pm 0.08$ \\
\hline Tocopherols & $\mathrm{mg} / 100 \mathrm{~g} \mathrm{dw}$ & & \\
\hline$\alpha$-tocopherol & $199.37 \pm 4.92$ & & \\
$\beta$-tocopherol & $0.56 \pm 0.00$ & & \\
$\gamma$-tocopherol & $2.28 \pm 0.10$ & & \\
$\delta$-tocopherol & $0.13 \pm 0.00$ & & \\
Total tocopherols & $202.34 \pm 5.02$ & & \\
\hline
\end{tabular}

dw- dry weight. SFA- Saturated fatty acids; MUFA- Monounsaturated fatty a Polyunsaturated fatty acids. 


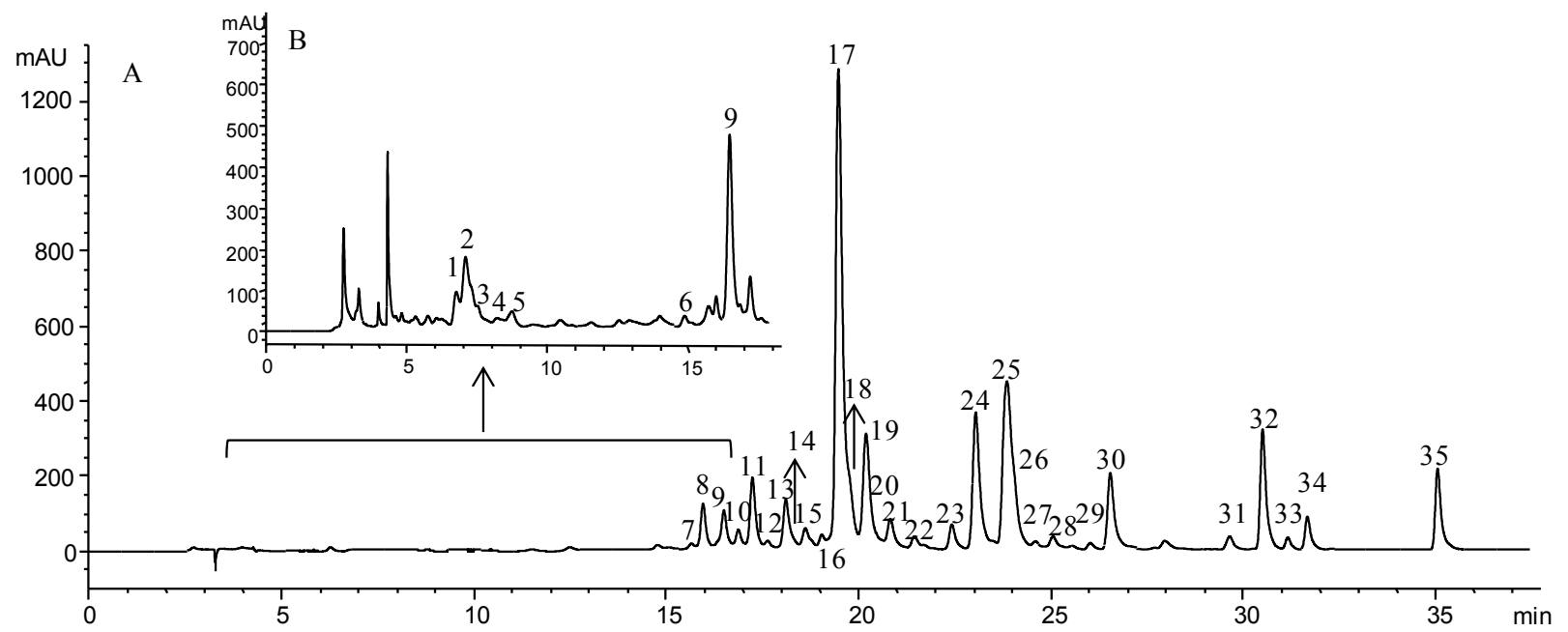

Figure 1. HPLC phenolic profile of Chenopodium ambrosiodes, obtained at $370 \mathrm{~nm}(\mathrm{~A})$ and 280 $\mathrm{nm}$ (B) for flavonoids and phenolic acids, respectively. 